\title{
Profile of Young Acute Myocardial Infarction in Chittagong Medical College Hospital, Chittagong
}

\author{
PK Das ${ }^{1}$, S Ghafur ${ }^{2}$, B Bhattacharjee ${ }^{1}$, A Dey $^{1}$, AL Mollah $^{1}$, SMM Kamal $^{1}$, AKMM Murshed $^{1}$ \\ ${ }^{1}$ Department of Cardiology, Chittagong Medical college Hospital, Chittagong. ${ }^{2}$ Department of \\ Cardiology, NICVD, Dhaka.
}

Keywords:

Myocardial

infarction, Young.

\begin{abstract}
:
Background: Coronary artery disease (CAD) is now an emerging epidemic in developing countries including Bangladesh. Younger people are being affected here more and more. Young individuals with acute myocardial infarction (AMI) may have unique presentation, risk factor, angiographic profile and outcome which may have an influence on the preventive strategies. This study is an attempt to investigate the same.
\end{abstract}

Methods: Young patients (aged d" 40 yrs) with AMI admitted to the coronary care unit of Chittagong Medical College Hospital over a period of one year were included in the study. Assessments of the patients were done with clinical history, physical examination and systemic evaluation. Location and types (STEMI, NSTEMI) of myocardial infarction were determined by ECG and serum troponin1 assay. Blood for glucose and lipid profile was drawn within 24 hours of admission. High sensitivity testing for C-reactive protein (hs CRP) was done in all patients. Coronary angiography was done within 6 weeks of hospital discharge.

Results: A total of 83 Patients with age d" 40 years were included .Age range were 21-40 years (34.21 \pm 5.07 yrs). There were 71 male (85.5\%). Male: female ratio was 5.9:1. Most of the young AMI patients presented lately to the hospital. Majority of these patients were thinly built, came from urban or semiurban areas, engaged in heavy physical activities and belonged to lower socioeconomic group. A positive family history of CAD was present in 18 patients $(28.68 \%)$. Smoking was the most prevalent risk factor followed by a raised serum triglyceride or low high density lipoprotein (HDL). A raised hs CRP was present in 47 patients (49.39\%). The overall in hospital mortality was only 3.61 $\%$. Coronary angiography done in 38 patients revealed single vessel disease in the majority.

Conclusion: The study focuses our attention to the rising incidence of AMI in young individuals who are less prone to CAD. Early detection of AMI and timely intervention needs high index of suspicion in this age group. These young patients have got low BMI High TG, Low HDG High hs CRP \& habit of smoking. Avoidance of smoking, controlling high TG and/or low HDL may reduce incidence of AMI among young patients. Use of high dose of statin at an early age in young persons with raised CRP may be considered.

(Cardiovasc.j. 2011; 4(1): 53-57)

\section{Introduction:}

In the threshold of the new millennium coronary artery disease $(\mathrm{CAD})$ is emerging as a new epidemic afflicting people of Indian subcontinent at a relatively young age. ${ }^{1}$ On average, people here develop myocardial infarction (MI) about 10 years earlier then other population ${ }^{2}$ and its occurrence in patients under 40 is 5 to 10 fold higher. ${ }^{3}$ The INTERHEART study showed that the mean age for first presentation of acute MI in the south Asians (Bangladesh, India, Nepal, Pakistan, Srilanka) population is 53 years, whereas that is Western Europe, China and Hong Kong is 63 years. ${ }^{4}$ These studies suggest that South Asians are at increased risk of MI at a younger age $(<40$ years). Death and disability due to MI in the productive year of life will greatly strain human and financial resources available to individuals, families and the society as a whole. A number of studies have examined the clinical and coronary angiographic profile of young with evidence of CAD. ${ }^{5,6}$ There is a relative paucity of information concerning the clinical features, risk factors, natural history and prognosis in young AMI patients. With increasing number of AMI among young in our country make this entity an important

Address of Correspondence : Dr. Prabir K. Das. Assistant professor of Cardiology, Chittagong Medical College, Chittagong, Bangladesh. 
clinical problem. Hence, the study is done to identify the epidemiologic, clinical and angiographic profile of young AMI patients in our country. This may help in defining the target of intervention and formulation of preventive strategies.

\section{Materials and Methods:}

The study was carried out in the department of Cardiology, Chittagong Medical College Hospital from March 01, 2010 to February 28, 2011. A total of 83 patient aged upto 40 years with the diagnosis of AMI were included. Consent from the patients and clearance from the hospital ethical committee were taken. Assessment of the patients were done, including information about age, gender, occupation, lifestyle, socioeconomic condition, mode of presentation, duration of symptoms and presence of risk factors for CAD. Detailed physical examination including anthropometric data, vital signs and complete systemic evaluation was recorded. Location and types of infarction (STEMI, NSTEMI) were determined by ECG and serum troponin - I assay. The criteria for diagnosis of MI were by the presence of at least two of the following; ${ }^{7}$ (i) $\mathrm{H} / \mathrm{O}$ typical chest pain $>30 \mathrm{~min}$ (ii) Characteristic ECG changes- a) $>0.1 \mathrm{mv}$ ST segment elevation or by evolution of pathologic $\mathrm{Q}$ of $>0.04$ sec duration in contiguous leads or c) $>0.1$ mv ST segment depression or definite T-wave inversion or both and (ii) the troponin $-^{2}>$ twice the upper limit. A person was considered to be hypertensive if he or she was taking antihypertensive treatment or was found to have a systolic blood pressure of e" $140 \mathrm{~mm} \mathrm{Hg}$ or a diastolic blood pressure of e" $90 \mathrm{mmHg} .{ }^{8}$ Blood for fasting glucose and lipid profile was drawn within 24 hours of hospital admission. An individual was considered to be diabetic if he or she is receiving insulin or oral hypoglycemic agents or had symptoms of diabetes with a random blood glucose $>200 \mathrm{mg} / \mathrm{dl}$ or fasting blood glucose of $>126 \mathrm{mg} /$ dl. ${ }^{9}$ Dyslipidaemia was defined when any of the lipid fraction was abnormal for example, serum cholesterol $>160 \mathrm{mg} / \mathrm{dl}$ or $\mathrm{HDL}<35 \mathrm{mg} / \mathrm{dl}$, LDL > $100 \mathrm{mg} / \mathrm{dl}$ or triglyceride $>150 \mathrm{mg} / \mathrm{dl} .{ }^{10} \mathrm{High}$ sensitivity testing for C-reactive protein was performed by using the CRP-latex immunoturbidometric assay (Denka, Seiken, Tokyo, Japan) having a minimal detectable concentration of $0.03 \mathrm{mg} / \mathrm{l} .{ }^{11} \mathrm{~A}$ family history was considered positive when symptomatic CAD occurred before age 60 in siblings, parents, parents siblings or grandparents.

The patients were treated with medications according to current recommendations. Thrombolytic therapy with streptokinsase was administered to all eligible patients presenting within 12 hours of onset of their chest pain. The average hospital stay was $10 \pm 3$ days. A predischarge echocardiogrphic examination to assess LV function was done in all patients.

We examined coronary angiography of 38 patients within a period of 6 weeks of hospital discharge in an attempt to ensure that the coronary anatomy reflects that present at the time of infarction. Coronary anatomy was described with the use of the criteria of the coronary artery surgical study (CASS). ${ }^{12}$

\section{Results}

A total of 83 patients presenting with AMI during the study period was studied. Demographic profile of the patient population is shown in table-I.

Table-I

Demographic profile of the patient population

\begin{tabular}{|c|c|}
\hline & \\
\hline Total No & $: 83$ \\
\hline Male & : $71(85.50 \%)$ \\
\hline Female & : $12(14.5 \%)$ \\
\hline Male : Female & $: 5.9: 1$ \\
\hline Age range & : $21-40$ yrs $(34.24 \pm 5.07)$ \\
\hline & $21-30$ yrs: $22(26.5 \%)$ \\
\hline & $31-40$ yrs: $61(73.5 \%)$ \\
\hline & Mean age among male: $32 \pm 6.13$ \\
\hline & Mean age among female: \\
\hline & $33.92 \pm 5.26$ \\
\hline Occupation & : Service holder - 26(31.32\%) \\
\hline & Businessmen- 17 (20.84\%) \\
\hline & Farmer-13 (15.66\%) \\
\hline & Driver- 09 (10.84\%) \\
\hline & Housewife-10 (12.04\%) \\
\hline & Other-8 $(9.63 \%)$ \\
\hline Habitat & $\begin{array}{l}: \text { Urban/Semi } \\
\text { urban-55 (66.26\%) }\end{array}$ \\
\hline & Rural- $28(33.75 \%)$ \\
\hline Socioeconomic & : Low middle class $-37(44.56 \%)$ \\
\hline Status & Middle class- 31 (37.34\%) \\
\hline & Poor-04 (4.81\%) \\
\hline & Rich-11 (13.22\%) \\
\hline Dietary habit & : Vegetarian-03 (3.61\%) \\
\hline & Non Vegetarian- 80 (96.38\%) \\
\hline
\end{tabular}


A previous history of angina pectoris was documented in only 14 patients (16.87\%). Most of the patients presented with typical symptoms of myocardial infarction. The mean duration of chest pain since presentation to $\mathrm{CCU}$ was $13.41 \pm 4.13$ hours.

Time interval between onset of chest pain and admission is shown in table-II.

\section{Table-II}

Duration of chest pain symptoms $(n=83)$

\begin{tabular}{lcc}
\hline Time & No & Percentage \\
\hline 0-6 hours & 21 & 25.30 \\
6-12 hours & 16 & 19.28 \\
12-24 hours & 33 & 29.76 \\
$>24$ hours & 13 & 15.66 \\
\hline
\end{tabular}

Majority patients i.e 46 patients (55.41\%) presented after 12 hours. Hence i.v. thrombolytic therapy was possible in only 26 patients (31.32\%).

The major risk factors for $\mathrm{CAD}$ are shown in tableIII.

Table-III

Major risk factors among the patients $(n=83)$

\begin{tabular}{lcc}
\hline Risk factor & No & Percentage \\
\hline Smoking & 50 & 60.24 \\
Dyslipidaemia & 41 & 49.34 \\
Hypertension & 21 & 25.30 \\
DM & 20 & 24.09 \\
Obesity & 07 & 08.40 \\
Raised hs CRP & 47 & 49.39 \\
F/H of CAD & 18 & 28.68 \\
\hline
\end{tabular}

Smoking was the most prevalent conventional risk factor followed by dyslipidaemia. Of the patients with dyslipidaemias, 32 patients had a raised triglyceride and /or a low high density lipoprotein (HDL) level. Nine patients had an elevated low density lipoprotein (LDL) only. Nearly equal numbers of patients (21 and 20) were hypertensive and diabetic. Among them, 12 had both the condition simultaneously. A family history of CAD was found in 18 patients. Seven patients $(8.40 \%)$ were obese with a body mass index $(\mathrm{BMI})>25$. They all had low HDL and high TG and easily met the criteria of metabolic syndrome. A raised hs CRP was found in 47 patients $(49.39 \%)$. Fifteen patients $(18 \%)$ had three or four risk factors. Six patients $(7.2 \%)$ had no risk factors for $\mathrm{CAD}$, of them one had essential thrombocythaemia.

The type and region of infarction is shown in tableIV.

Table-IV

Type and region of infarction $(n=83)$

\begin{tabular}{llcc}
\hline Type & Region & No & Percentage \\
\hline STEMI & Anterior & 39 & 46.98 \\
& Inferior & 33 & 39.75 \\
& Combined (Ant+inf) & 05 & 6.02 \\
\multicolumn{2}{l}{ NSTEMI } & 06 & 7.22 \\
\hline
\end{tabular}

Most of the patients (74 i.e. 89.16\%) had normal systemic examination at presentation and during hospital stay. Signs of left ventricular failure (basal crepitation $\pm S_{3}$ gallop) were found in 4 patients. Five patients developed cardiogenic shock of whom 3 died. In hospital mortality was $3.16 \%$. Two patients developed ventricular tachycardia reverted by dc cardioversion. Complete heart block developed among 2 of the patients with inferior wall MI, which reverted to sinus rhythm conservatively.

In hospital complications are shown in table -V.

Table-V

In hospital complications ( $n=83$ )

\begin{tabular}{lcc}
\hline Type & No & Percentage \\
\hline Acute LVF & 4 & 4.82 \\
Carcinogenic shock & 5 & 6.02 \\
Ventricular tachycardia & 2 & 2.41 \\
AV block & 2 & 2.41 \\
\hline
\end{tabular}

LVF= Left Ventricular Failure

Coronary angiography was possible in 32 patients. CAG findings are shown in table-VI. 
Table-VI

Coronary angiography findings $(n=38)$

\begin{tabular}{lcc}
\hline Type and leison & No & Percentage \\
\hline SVD & 17 & 44.83 \\
DVD & 6 & 15.78 \\
TVD & 8 & 21.05 \\
Normal & 7 & 18.42 \\
\hline
\end{tabular}

SVS $=$ Single Vessel Disease, DVD $=$ Double Vessel Disease, TVD= Tripple Vessel Disease.

Out of 34 patients, 24(63.25\%) patients had single or zero vessel disease (stenosis $>70 \%$ luminal diameter). Fourteen Patients (36.83\%) had multivessel disease.

\section{Discussion:}

Although MI is usually the disease of people over 40 years of age, an increasing number of younger patients are being hospitalized with AMI. This increased prevalence among young adults can be partly attributed to the increased prevalence of risk factors. ${ }^{13}$ The present study shows that young patients with MI constitute a distinct group with characteristic clinical presentation, risk factor, angiographic profile and low hospital mortality. This study highlights the importance of male sex, family history, cigarette smoking, dyslipidaemia, increased hs CRP as risk factor for MI among young's. There is a clear male preponderance, with a male female ratio of 5.9:1 in our study which is in agreement with previous studies, suggesting that it is predominantly a disease of men. ${ }^{14}$ Majority of our patients (72 i.e $86.74 \%$ ) belonged to middle and lower socioeconomic status and most of them were engaged in heavy physical activities. These findings are in agreement with that of Indian studies ${ }^{5}$. We found smoking as the most common risk factor (60\%) Zimmerman $\mathrm{FH}$, et al also found smoking as the most common risk factors in young AMI patients. ${ }^{6}$ None of our females with AMI were smoker. The INTERHERRT study also observed that smoking is a greater risk factor in young men then women. ${ }^{4}$ The risk of MI increases incrementally with smoking. Other epidemiologic studies from India also suggest a greater association of smoking with CAD in younger individuals. ${ }^{15}$ Dyslipidaemia was found to be the second commonest conventional risk factor in our study. Majority had a raised triglyceride and/or a low HDL level. This is in agreement with that of Gupta R, et al, ${ }^{16}$ who stated that lower HDL and higher TG level in both young and older cases appear to be a hallmark of the Indian population manifesting CAD. Brian D, et al found dyslipidaemia less often among their young AMI patients who belonged to western population. ${ }^{17} \mathrm{~A}$ positive family history of CAD was found among 18 patients (28.68\%). A previous study has reported a greater familial influence in the development of MI in young compared with older patients. ${ }^{18} \mathrm{~A}$ positive family history has emerged as an important independent risk factor for $\mathrm{CAD}$ in young cases in Indian studies, ${ }^{4,19}$ where it was the most important risk factor. A raised hs CRP (> 3mg/l) was found in 47 patients $(49.59 \%)$ which was the second commonest risk factor (both conventional and emerging) found among our patients. Estimation of hs CRP may identify high risk subgroups that are likely to be benefited from statin therapy especially in whom overt dyslipidaemia is not present. ${ }^{11}$ In 6 patients $(7.2 \%)$ no obvious risk factors was found to account for MI. Brian D, et al found this feature among $7 \%$ of their young patients with MI. ${ }^{17}$ Out of 38 patients with coronary angiography 24 patients (63.25\%) had single or zero vessel disease in our series, Brain D, et al found the same as $63 \%$ among their young patients. ${ }^{17}$ Conversely, three vessel diseases were present in $21 \%$ where it was $17 \%$ in study by Brain D, et al. These studies are also consistent with other studies that have demonstrated less coronary artery disease in young patients ${ }^{12}$. Despite late presentation (55\% after 12 hours) and lower rate of thrombolytic administration (31.32\%) in hospital mortality was only $3.6 \%$ among our patients which is in accordance with findings of Brian D et al, who found it as $2.5 \% .{ }^{17}$

\section{Conclusion:}

In order to combat the onslaught of $\mathrm{CAD}$ among our young population and to reduce AMI and its associated complications it is mandatory to have a high index of suspicion, particularly in those who present with atypical symptoms. Evaluation for conventional and emerging risk factors must be done from age 18 and onward. In asymptomatic person with background of risk factors stress ECG, stress echo / stress thallium scan must be periodically performed. In subjects with exercise induced reversible ischaemia CAG must be done. 
In symptomatic individuals mandatory CAG must be done to delineate the culprit lesion for timely and appropriate intervention. From Bangladesh point of view, there is a need to plan strategies for preventing and halting coronary atherosclerosis which is fast spreading as a malignant epidemic among the young. A strategy involving prevention of CAD long before their onset will be more cost effective than providing interventions at a stage when the disease is well established.

\section{Recommendations:}

- Screening for CAD risk factors by age 18 and/ or at the earliest opportunity available.

- High sensitivity CRP testing should be considered along with testing for other conventional risk factors.

- Early administration of high dose statin in dyslipidaemic young and/or those with raised hs CRP may provide primary prevention.

- Treatment goal should be lower e.g LDL $<100 \mathrm{mg} / \mathrm{dl}(<70 \mathrm{mg} / \mathrm{dl}$ in CAD), TG $<150 \mathrm{mg} / \mathrm{dl}$, $\mathrm{TC}<160 \mathrm{mg} / \mathrm{dl}$.

\section{References:}

1. Janus ED, Postglione A, Singh RS, et al. The moderanisation of Asia. Implication of coronary artery disease. Circulation 1996; 94: 2671-3.

2. Mammi MVI, Pavithram K, Abdurahman P, et al. Acute myocardial infraction in North Kerala - a 20 years hospital based study. Indian Heart journal 1991; 343: 93-96.

3. Hughes LO, Ravel U, Raftery E, First myocardial infarction in Asian and white men. BMJ 1989; 295: $1345-1350$.

4. Yusuf S, Hawkan S, Ounpue S, et al. Effect of potentially modifiable risk factors associated with MI in 52 countries (the INTERHEART study) : case control study. Lancet 2004; 364: 937-67.

5. Siwash SB, Singh H, Sharma D, Katyal VK. Profile of young acute myocardial infraction in Harayana. JAPI 1998 May; 46(5): 424-6.

6. FH Zimmerman, A Cameron, LD Fisher. Myocardial infarction in young adults: angiographic characterization, risk factors and prognosis (Coronary artery surgery registry). J Am Coll Cardiol 1995; 26: 654-661.

7. Ryan TJ, Anderson JL, Antman EM, et al. ACC/AHA guideline for the management of patients with acute myocardial infarction. A report of the American College of Cardiology / American Heart association task force on practical guidelines (Committee on management of acute myocardial infraction). J Am Coll Cardiol 1996; 28: $1328-1428$.

8. Chobanian AV, Bakriz GL, Black HR, et al. Seventh report of the joint National Committee on Prevention, Detection, Evaluation and Treatment of High Blood Pressure. Hypertension 2003; 42: 1206-1252.

9. American Diabetic Association Diagnosis and Classification of Diabetes Mellitus. Diabetic Care 2005; 28 (Supp 12): 537-542.

10. Enas EA, Senthilkumar A. Coronary artery disease in Asian Indians : an update and review. Internet $J$ Cardiol 2002; 1(2): 10-24.

11. David A, Morrow, James A, et al. Clinical relevance of C-reactive protein during followup of patients with acute coronary syndromes in aggrastat to Zocor trial. Circulation 2006; 114: 281-288.

12. CASS Principal investigators and their associates: Coronary artery surgery study(CASS) : A randomized trial of coronary artery bypass surgery survival data. Circulation 1983; 68: 939.

13. Egred M, Viswanalhan G, David GK. Myocardial Infarction in young adults. Postgraduate Med $J$ 2005; 81: 741-5.

14. Choudhury L, March D, Myocardial Infarction in young patients. Am J Med 2999; 107: 254-61.

15. Maity AK, Das MK, Chatterjee SS, et al. Prognostic Significance of risk factors in AMI in young. Indian Heart Journal 1989; 41: 188-91.

16. Gupta R, Gupta VP, Soma M, et al. Prevalence of CAD and risk factors in an urban Indian population. Jaipur Heart Watch-2. Indian Heart Journal 2002; 54: 37-66.

17. Brian D, Hoit MD, Elizabeth A, et al. Myocardial infarction in young patients: an analysis by age subset. Circulation 1986; 74(4): 712-721.

18. Rissanen AM: Familial occurrence of coronary artery disease: effect of age at diagnosis. Am J Cardiol 44; 60, 1979.

19. Kaul RV, Dogit FB, Manchandra SC, et al. Myocardial infarction in young Indian patients: risk factors and coronary angiographic profile. Am Heart Journal 1986; 12: $171-5$. 